\title{
Female fertility in Hippodamia convergens (Coleoptera: Coccinellidae) is maximized by polyandry, but reduced by continued male presence
}

\author{
Mohamed H. BAYOUMY ${ }^{1,2}$ and J.P. MICHAUD ${ }^{2, *}$ \\ ${ }^{1}$ Mansoura University, Faculty of Agriculture, Economic Entomology Department, Mansoura 35516, Egypt; \\ e-mail:mhmohamed@mans.edu.eg \\ ${ }^{2}$ Agricultural Research Center-Hays, Department of Entomology, Kansas State University, 1232 240th Ave, Hays, KS 67601, USA; \\ e-mail:jpmi@ksu.edu
}

Key words. Coleoptera, Coccinellidae, Hippodamia convergens, fecundity, fertility, female choice, polyandry, monogamy, paternal effects, reproductive success

\begin{abstract}
Many species of lady beetles are highly promiscuous and females mate repeatedly even when not sperm-limited. We quantified female reproductive success and progeny development in Hippodamia convergens using a laboratory experiment designed to test whether (1) male novelty (different males), (2) male mating status (virgin, non-virgin) or (3) opportunities for female mate choice, would increase female fitness compared to a similar number of matings with the same male. Daily access to novel males, regardless of their mating status, increased the egg fertility of females, but not their fecundity. Opportunities for mate choice did not improve any measure of female reproductive success compared to arbitrary assignment of males, but slightly increased reproductive rate, as measured by the number of days to produce 15 clutches. The eggs of monogamous females had the fastest eclosion times, but larval development was fastest for progeny of females polyandrous with non-virgin males, and total developmental time did not differ among treatments. In a second experiment, confinement with two males during oviposition disrupted egg clustering and reduced egg fertility, but not female fecundity, relative to confinement with one male or oviposition in solitude, suggesting a negative impact of male harassment on female fitness in the presence of multiple males. However, the continued presence of two males also improved progeny survival and reduced progeny development time relative to female confinement with one, likely due to summation of paternal effects when females were allowed unlimited matings with both males. These results do not rule out genetic benefits of polyandry, but support the view that enhanced egg fertility is a primary benefit, and suggest more subtle benefits may be obtained in the form of additive paternal effects. The average number of female matings in nature may even exceed that required to obtain such benefits if females use "convenience polyandry" to diminish male harassment.
\end{abstract}

\section{INTRODUCTION}

Throughout much of the $20^{\text {th }}$ century, sexual selection theory rested on the premise that male reproductive success was limited by access to females, whereas female reproductive success was limited by access to resources that can be converted into offspring, rather than by access to sperm (Trivers, 1972; Jennions \& Kokko, 2010). However, there is growing evidence that females may receive various material benefits from males apart from sperm, and that mating with multiple males can improve female reproductive success in various ways unrelated to sperm limitation (Ridley, 1988; Hunter et al., 1993; Jennions \& Petrie, 2000; Tregenza \& Wedell, 2000; Hosken \& Stockley, 2003; Simmons, 2005). It is therefore not surprising that females of many species mate repeatedly even when not sperm-limited (Arnqvist \& Nilsson, 2000). There is also extensive and growing evidence of post-copulatory mechanisms of female choice (Eberhard, 1996, 1997); females may utilize various mechanisms to influence the outcome of sperm competition, and thus offspring quality (Olsson et al., 1996). Therefore, there may be qualitative benefits of polyandry for female fertility even in the absence of fecundity benefits (Jennions \& Petrie, 2000; Tregenza \&
Wedell, 2002; Hosken \& Stockley, 2003; Hosken et al., 2003), and there is now abundant evidence from many taxa that multiple maternal matings can improve offspring fitness in various ways, both genetic and epigenetic (Madsen et al., 1992; Olsson et al., 1996; Tregenza \& Wedell, 1998; Fisher et al., 2006; Parker \& Birkhead, 2013). For example, in coccinellid beetles, paternal effects on offspring fitness may be functionally linked to fecundity stimulation and can vary with male mating status (e.g., Michaud et al., 2013; Mirhosseini et al., 2014).

Promiscuity, i.e., multiple matings by both males and females, is not uncommon in insects, but is particularly prevalent in the Coccinellidae (Majerus, 1994; Srivastava \& Omkar, 2005; Hadrill et al., 2008). The ability of repeated matings by coccinellid males to stimulate female fecundity has also been demonstrated, first in Adalia bipunctata L. (Semyanov, 1970), and subsequently in other Palearctic and Asian species (Majerus, 1994; Omkar \& Mishra, 2005a; Omkar \& Pervez, 2005; Bind, 2007; Omkar et al., 2010). When male investment in ejaculates is high, virgin males can be capable of stronger female reproductive stimulation than previously-mated males, due to depletion of male factors as a function of sexual activ-

\footnotetext{
* Corresponding author.
} 
ity (e.g., Michaud et al., 2013). Further, if females benefit from the opportunity to select mates, then female reproductive potential should be improved by providing females a choice of various males compared to an arbitrary mate assignment. For example, Pervez \& Maurice (2011) found that females of Hippodamia variegata (Goeze), selectively mated more often with some males than with others when provided with a choice of four potential mates. These females also achieved greater reproductive success when compared to monandrous females or those mated arbitrarily to different males. The authors attributed their results to opportunities for female choice in the five male treatment, but the experimental design did not control for number of matings; polyandrous females with choice were able to mate at will during a $9 \mathrm{~h}$ period, whereas females in other treatments were limited to single daily matings. Thus, the apparent reproductive benefits of polyandry with mate choice in this case are more likely a result of additive fecundity stimulation as a function of multiple matings, rather than a result of females choosing better males. The benefits of multiple matings are also consistent with the observed paternal effects on progeny development in these data. A more convincing demonstration of female choice benefits is provided by Omkar \& Mishra (2005b) for Propylea dissecta (Mulsant); although number of matings was again not controlled for polyandrous females in the choice treatment, the prolonged duration of copula in this species would seem to have limited matings to one per day. Once again, results for offspring development and survival were indicative of complementary paternal effects on the offspring of polyandrous females. Finally, if there is conflict between males and females over mating frequency, then male harassment may exact a cost to ovipositing females. For example, male harassment has been shown to drive female dispersion among host plant patches in the butterfly Euphydryas anicia Doubleday (Lepidoptera: Nymphalidae) (Odendaal et al., 1989). In Echinothrips americanus (Morgan) (Thysanoptera: Thripidae), post-mating male harassment reduces both female fecundity and longevity, even though the frequency of female remating is relatively low (Li et al., 2014).

Despite the economic importance of many nearctic coccinellids, relatively few studies have addressed their reproductive biology in the context of polyandry. The convergent lady beetle, Hippodamia convergens Guerin-Meneville, is a nearctic species widely distributed in the western hemisphere that has been studied extensively for its biological control contributions in many cropping systems (Rice \& Wilde, 1988; Nechols \& Harvey, 1998; Michaud, 2013). Like most coccinellids, it has a promiscuous mating system with both males and female mating repeatedly with multiple partners. It is also a species demonstrating age-specific maternal effects in which the developmental phenotypes of progeny are altered in a fixed pattern as a function of oviposition sequence (Vargas et al., 2012a, b). Using H. convergens, experiments were designed to test the following hypotheses: (H1) A series of matings with different males will improve female fecundity and fertility compared to a similar number of matings with the same male; (H2) A series of matings with virgin males will have greater impact on female reproductive stimulation than will a similar series of matings with previously mated males (because seminal contributions from virgin males will be greater); (H3) female reproductive success will be improved if females are able to select mates from a group of alternative males for each of a series of matings, as opposed to being arbitrarily assigned a male. Furthermore, we hypothesized that paternal effects on offspring development might vary among males both qualitatively, as a function of genotype and phenotype, and quantitatively, as a function of mating status, generating two further hypotheses: (H4) matings with multiple males will increase progeny fitness, as inferred by eclosion rate, developmental time, and/or final body size because of additive or complementary paternal effects obtained from different males and; (H5) matings with a series of virgin males will increase progeny fitness more than a similar series of matings with previously mated males (because of male factor depletion as a function of mating). In a separate experiment, we tested one additional hypothesis; (H6) female reproductive success will decline with increasing male presence during oviposition because of increasing levels of male harassment.

\section{MATERIAL AND METHODS}

\section{Insects}

A stock colony of $H$. convergens was established from ca. 90 adults collected from a sunflower field in Hays, KS, USA $\left(38^{\circ} 51^{\prime} \mathrm{N}, 99^{\circ} 20^{\prime} \mathrm{W}\right)$, in April, 2013 by dislodging them from plants directly into ventilated, clear plastic vials $(4.5 \mathrm{~cm}$ diam $\times$ $9.0 \mathrm{~cm} \mathrm{ht}=143 \mathrm{~cm}^{3}$ ). Following transfer to the laboratory, the insects were held in a growth chamber set to $16 \mathrm{~L}: 8 \mathrm{D}$ photoperiod and a constant temperature of $23.0 \pm 1.0^{\circ} \mathrm{C}$. Adult females were isolated in polystyrene vials (as above) and fed greenbug, Schizaphis graminum (Rondani), to induce oviposition. Greenbugs were reared on sorghum seedlings in a growth chamber set to $16 \mathrm{~L}: 8 \mathrm{D}$ photoperiod and a constant temperature of $22.0 \pm 1.0^{\circ} \mathrm{C}$ to provide a continuous source of food for females. Female $H$. convergens laid their eggs on the inner surfaces of the containers and egg clusters were collected daily by transferring the beetles to new vials. Larvae of the first laboratory generation were labelled according to their maternal lineage and reared in Petri dishes (5.5 $\mathrm{cm}$ diam.) in sibling groups of five on an ad libitum diet of frozen eggs of the flour moth, Ephestia kuehniella Zeller (Lepidoptera: Pyralidae), with water provided on a small cube of sponge, both refreshed daily. All larvae were held in a growth chamber under the same physical conditions as the adults. Once adults emerged, they were sexed, isolated in Petri dishes, and labelled according to their identity and maternal lineage to prevent the pairing of siblings. These adults were then used as parents in the experiments, which were carried out under the same physical conditions as described above.

\section{Polyandry}

This experiment was designed to test the effects of polyandry with different types of males on the reproductive performance of females, including a control group of monogamous females. All experimental females were virgin and 10 days old upon first mating and all males were of similar age to females $( \pm 1 \mathrm{~d})$ and virgin on their first day of mating, except where otherwise specified. Four treatments $(n=12$ females per treatment) were imple- 
TABLE 1. Mean ( \pm SE) fecundity, egg fertility and number of days required to produce 15 clutches for Hippodamia convergens females subjected to one of four different daily mating treatments for five days: T1, monogamy (five matings with a single male), T2, no-choice polyandry with virgin males (five matings with different virgin males), T3, no-choice polyandry with non-virgin males (five matings with different previously-mated males) and, T4, mate choice polyandry with non-virgin males (choice of four previouslymated males in each of five matings). Asterisks indicate significant differences in planned pairwise comparisons (ANOVA, $\alpha=0.05)$.

\begin{tabular}{lcccc}
\hline & $\mathrm{T} 1$ & $\mathrm{~T} 2$ & $\mathrm{~T} 3$ & $\mathrm{~T} 4$ \\
\hline $\mathrm{n}$ & 12 & 11 & 10 & 11 \\
Fecundity (no. eggs) & $452.1 \pm 23.3$ & $433.6 \pm 32.0$ & $357.1 \pm 42.0$ & $423.1 \pm 26.1$ \\
Egg fertility (\%) & $70.8 \pm 2.2^{*}$ & $78.4 \pm 2.7^{*}$ & $79.6 \pm 2.4$ & $83.1 \pm 1.5$ \\
Days to 15 clutches & $17.1 \pm 0.6$ & $18.1 \pm 1.1$ & $20.1 \pm 1.6^{*}$ & $16.5 \pm 0.7^{*}$ \\
\hline
\end{tabular}

mented: (1) females were each permitted a single daily mating with the same male for five days (monogamy); (2) females were each permitted single daily matings with a series of five different virgin males over five days (polyandry with virgin males, no mate choice); (3) females were each permitted single daily matings with a series of five different, previously-mated males (polyandry with non-virgin males, no mate choice) and; (4) females were each permitted a single daily mating with their choice of one of four non-virgin males for five days (polyandry with mate choice among non-virgin males). Prior to use in the experiment, and in between matings with experimental females, non-virgin males were paired with unrelated females in Petri dishes $(5.5 \mathrm{~cm}$ diam). Insects were paired in Petri dishes (as above) with Ephestia eggs for one successful copulation. Because of time constraints, pairs were separated once they disengaged genitalia, even though males may remain with females for some time following completion of copula.

After each mating, females were isolated in ventilated plastic vials (as above) and provisioned with excised sorghum seedlings infested with greenbugs, refreshed daily. Eggs were collected daily, counted, and held under the same physical conditions as adults until eclosion to determine their viability. A total of 15 days of oviposition (= "clutches") were collected from each female. In order to assess possible differences in paternal effects resulting from these mating treatments, a series of 10 progeny from the first clutch of each female were reared to adulthood and their developmental data recorded. These larvae were monitored twice daily throughout their development to record as accurately as possible the periods required for eclosion, larval development, and pupation. The number of larval molts was also recorded, as a small proportion of individuals may undergo either three or five instars, as opposed to the normal four. Upon emergence, adults were sexed and then weighed on an analytical balance.

\section{Male presence}

Newly-emerged adult beetles were sexed, isolated in Petri dishes $(5.5 \mathrm{~cm}$ diam) and fed ad libitum eggs of E. kuehniella with water provided on a small cube of sponge. When beetles were 10 days old females were confined individually in ventilated plastic cylinders (as above) and assigned to one of three different treatments ( $n=12$ per treatment): (1) females were allowed a single copulation daily with the same unrelated, initially virgin male and otherwise held in solitude; (2) females were confined with an unrelated, initially virgin male; (3) females were confined with two unrelated, initially virgin males. All beetles were provisioned ad libitum with greenbugs on sorghum seedlings, refreshed daily, as this food is more suitable than eggs of E. kuehniella for eliciting oviposition in this species. All eggs laid were collected daily until 10 clutches had been obtained from each female; data for females that died before producing 10 clutches (one female in treatment 2, two in treatment 3) were excluded from analyses of fecundity and fertility. Eggs were held until eclosion and the percentage hatching was recorded. In addition, a series of 10 larvae were reared from the first clutch produced by each female and data recorded on their survival, developmental time, sex and adult fresh mass at emergence. Females were followed up to 15 clutches for survival analysis.

\section{Statistical analysis}

The results of the polyandry experiment were analyzed as a series of a priori pairwise comparisons using one-way ANOVA: T1 vs T2 (monogamy vs polyandry with virgin males), T2 vs T3 (polyandry with virgin males vs non-virgin males), and T3 vs T4 (polyandry with non-virgin males, mate choice vs no mate choice). Data on female fecundity, fertility and the number of days required to obtain 15 clutches, were analyzed for planned comparisons using one-way ANOVA. The proportion of females surviving until production of 15 clutches was analyzed using the

TABLE 2. Mean ( \pm SE) developmental parameters for progeny of Hippodamia convergens females subjected to four different mating treatments for five days: T1, monogamy (five matings with a single male), T2, no-choice polyandry with virgin males (five matings with different virgin males), T3, no-choice polyandry with non-virgin males (five matings with different previously-mated males) and, T4, mate choice polyandry with non-virgin males (choice of four previously-mated males in each of five matings). A series of 10 offspring were reared from the first clutch of each female in each treatment $(n=11)$.

\begin{tabular}{|c|c|c|c|c|}
\hline \multirow{2}{*}{ Dependent variable } & \multicolumn{4}{|c|}{ Mating treatment } \\
\hline & $\mathrm{T} 1$ & $\mathrm{~T} 2$ & $\mathrm{~T} 3$ & $\mathrm{~T} 4$ \\
\hline Eclosion time (d) & $3.00 \pm 0.00^{*}$ & $3.07 \pm 0.03^{*}$ & $3.04 \pm 0.01$ & $3.06 \pm 0.02$ \\
\hline Larval development time (d) & $11.6 \pm 0.10$ & $11.6 \pm 0.14^{*}$ & $11.2 \pm 0.10^{*}$ & $11.2 \pm 0.13$ \\
\hline Pupation time (d) & $5.5 \pm 0.07$ & $5.5 \pm 0.06$ & $5.6 \pm 0.06$ & $5.5 \pm 0.05$ \\
\hline Total development time (d) & $20.1 \pm 0.11$ & $20.2 \pm 0.14$ & $19.9 \pm 0.11$ & $19.8 \pm 0.14$ \\
\hline Male fresh mass (mg) & $15.0 \pm 0.33$ & $15.0 \pm 0.26$ & $15.4 \pm 0.26$ & $15.3 \pm 0.30$ \\
\hline Female fresh mass (mg) & $17.1 \pm 0.32$ & $17.9 \pm 0.36$ & $18.1 \pm 0.52$ & $17.7 \pm 0.19$ \\
\hline
\end{tabular}

Asterisks indicate significant differences (ANOVA, $\alpha=0.05$ ) between planned pairwise comparisons. 

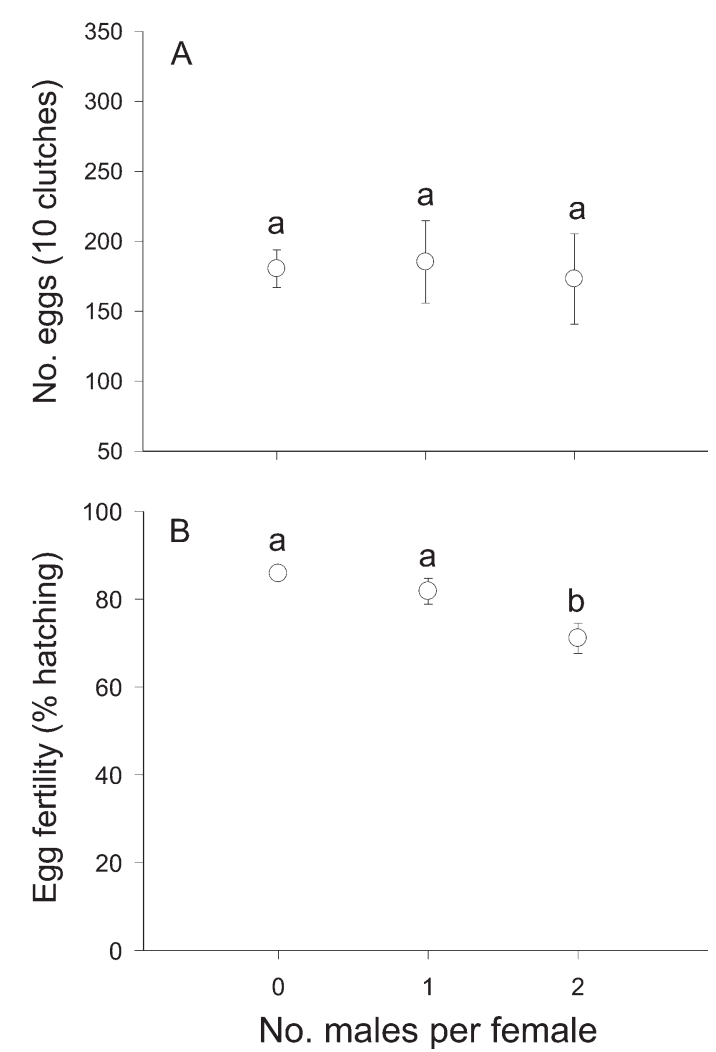

Fig. 1. Mean ( \pm SE) 10 clutch fecundities $(A)$ and egg fertilities (B) of Hippodamia convergens females $(\mathrm{n}=12,11$ and 10 , respectively) subjected to three different levels of male presence during oviposition.

Kaplan-Meier estimation. The proportions of progeny surviving to adulthood were compared among treatments using a sample size-weighted, two-tailed test of proportions (Statistica, 2000).

\section{RESULTS}

\section{Polyandry}

The fecundity of monogamous $H$. convergens females was not significantly different from that of females polyandrous with virgin males (T1 vs T2: $F=0.22$; df $=1,21$; $P=0.64$; Table 1$)$, nor was it affected by the mating status of the males (T2 vs T3: $F=2.10$; df $=1,20 ; P=0.16$ ), or the opportunity for female choice (T3 vs T4: $F=1.78$;

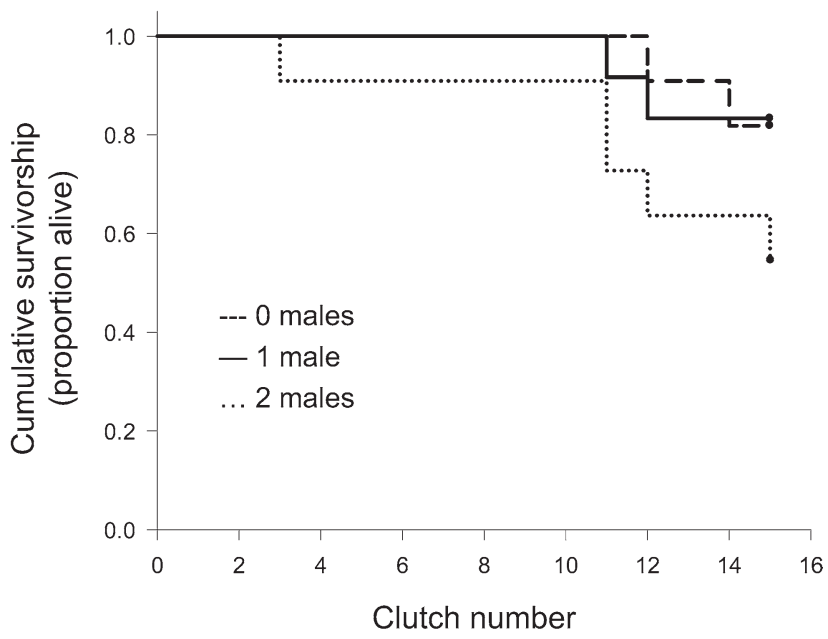

Fig. 2. Cumulative survivorship of Hippodamia convergens females subjected to three different levels of male presence during oviposition based on Kaplan-Meier estimation and log-rank tests.

df $=1,20 ; P=0.197)$. However, polyandry improved egg fertility compared with monogamy (T1 vs T2: $F=4.86$; df $=1,21 ; P=0.039$ ), although egg fertility was unaffected by male mating status (T2 vs T3: $F=0.11$; $\mathrm{df}=1,20 ; P=$ 0.739 ) or female ability to choose mates (T3 vs T4: $F=$ $1.53 ; \mathrm{df}=1,20 ; P=0.231)$. The same series of planned comparisons revealed a significant effect of mate choice on the rate of female oviposition, as estimated by the number of days required to produce 15 clutches (T1 vs T2: $F=$ $0.69 ; \mathrm{df}=1,21 ; P=0.416 ; \mathrm{T} 2$ vs T3: $F=1.12 ; \mathrm{df}=1,20 ; P$ $=0.303$; T3 vs T4: $F=4.67$;f $=1,20 ; P=0.047)$; females allowed to choose males produced 15 clutches in the shortest period.

Survivorship of progeny was $80 \%$ in the monogamy treatment (T1), which was marginally higher $(P=0.056)$ than that of progeny in the polyandry treatment with virgin males (T2, 69\%). Progeny survivorship was 77\% in T3 (polyandry with non-virgin males) which was not significantly different from T2 $(P=0.195)$ or T4 $(74 \%, P=$ $0.615)$. Treatment affected eclosion time of eggs $(F=3.81$; df $=3,326 ; P=0.010)$ and larval development time $(F=$ 3.26 ; df $=3,326 ; P=0.022)$, but not pupation time $(F=$ $0.58 ; \mathrm{df}=3,326 ; P=0.626)$ or total development $(F=$

TABLE 3. Mean ( \pm SE) developmental parameters for progeny of Hippodamia convergens females subjected to three different levels of male presence during oviposition: T1 - single daily copulations with the same male, followed by female isolation, T2 - female confined with one male, and T3 - female confined with two males. Values followed by the same letter were not significantly different among treatments (ANOVA followed by Fisher's LSD, $\alpha=0.05$ ). A series of 10 offspring were reared from the first clutch of each female in each treatment $(\mathrm{n}=12,11$ and 10 , respectively).

\begin{tabular}{lccc}
\hline & \multicolumn{3}{c}{ No. males present during oviposition } \\
\hline Dependent variable & 0 & 1 & 2 \\
Eclosion time (d) & $3.11 \pm 0.03 \mathrm{~b}$ & $3.01 \pm 0.04 \mathrm{c}$ & $3.27 \pm 0.04 \mathrm{a}$ \\
Larval development time (d) & $12.2 \pm 0.13 \mathrm{a}$ & $12.0 \pm 0.11 \mathrm{a}$ & $11.6 \pm 0.12 \mathrm{~b}$ \\
Pupation time (d) & $5.6 \pm 0.06 \mathrm{a}$ & $5.6 \pm 0.06 \mathrm{a}$ & $5.6 \pm 0.06 \mathrm{a}$ \\
Total development time (d) & $20.9 \pm 0.12 \mathrm{a}$ & $20.6 \pm 0.13 \mathrm{a}$ & $20.4 \pm 0.13 \mathrm{~b}$ \\
Male fresh mass (mg) & $14.1 \pm 0.24 \mathrm{a}$ & $14.7 \pm 0.45 \mathrm{a}$ & $14.6 \pm 0.27 \mathrm{a}$ \\
Female fresh mass (mg) & $17.3 \pm 0.49 \mathrm{a}$ & $17.6 \pm 0.41 \mathrm{a}$ & $21.3 \pm 3.41 \mathrm{a}$ \\
\hline
\end{tabular}

Values bearing the same upper case letters were not significantly different (ANOVA, $\alpha=0.05$ ) between clutches within columns; values bearing the same lower case letters were not significantly different (LSD, $\alpha=0.05$ ) among mating treatments within rows. 
2.35; df $=3,326 ; P=0.072$ ). Monogamy resulted in the fastest eclosion of eggs, although it was not significantly faster than polyandry with non-virgin males. Polyandry with non-virgin males yielded the fastest larval development, whether or not females were permitted to choose mates (Table 2). There was no effect of treatment on adult fresh mass of males $(F=0.48 ; \mathrm{df}=3,160 ; P=0.695)$ or females $(F=1.27$;f $=3,162 ; P=0.285)$.

\section{Male presence}

Increasing the number of males present $(0,1$ and 2$)$ during female oviposition did not significantly affect female fecundity $(F=0.27 ; \mathrm{df}=2,30 ; P=0.762)$, and although it tended to increase the number of days required to obtain 10 clutches, the differences among means were not significant (T1: $12.5 \pm 1.0 \mathrm{~d}, \mathrm{~T} 2: 14.5 \pm 2.1 \mathrm{~d}, \mathrm{~T} 3: 19.3 \pm 3.3 \mathrm{~d} ; F=$ $2.45 ; \mathrm{df}=2,30 ; P=0.104)$. However, increasing the number of males present reduced egg fertility $(F=8.67$; df $=$ $2,30 ; P=0.001$; Fig. 1$)$. There was a trend toward reduced female survivorship with increased male presence (Fig. 2), but it was not significant $\left(\chi^{2}=3.47 ; \mathrm{df}=2 ; P=0.18\right)$.

Survivorship of progeny in the 0,1 , and 2 male treatments was $77.5 \%, 67.3 \%$, and $82.7 \%$, respectively, the only significant difference being between treatments 2 and 3 ( 0 vs 1 male: $P=0.085$, 0 vs 2 males: $P=0.140,1$ vs 2 males: $P=0.010)$. Increasing male presence significantly affected the eclosion time of eggs $(F=16.23$; df $=2,255$; $P<0.001)$, larval development time $(F=7.27 ; \mathrm{df}=2,255$; $P=0.001)$ and total developmental time $(F=4.33$; df $=$ $2,255 ; P=0.014)$, but not pupation time $(F=0.35$; df $=$ 2,255; $P=0.702)$. The longest eclosion time, but shortest larval and total development times all occurred in the treatment with two males continuously present (Table 3 ). There was no effect of treatment on the fresh mass of males ( $F$ $=1.28 ; \mathrm{df}=2,123 ; P=0.283)$ or females $(F=0.99 ; \mathrm{df}=$ 2,129; $P=0.374)$.

\section{DISCUSSION}

Daily matings with a series of different males increased the egg fertility of $H$. convergens females in comparison to a similar number of matings with the same male, supporting our first hypothesis that matings with novel males would improve female reproductive success compared to a similar number of matings with the same male. Improved egg fertility is perhaps the most widely demonstrated female benefit of polyandry when a broad range of studies spanning many taxa is considered (Slatyer et al., 2012). Reproductive benefits of polyandry have now been demonstrated in many lady beetle species including $A$. bipunctata, Propylea quatuordecimpunctata (L.), Harmonia quadripunctata (Pontoppidan) (Majerus, 1994), Cheilomenes sexmaculata (F.) (Bind, 2007), Coccinella septempunctata L. (Omkar \& Srivastava, 2002), Coccinella transversalis F. (Omkar \& James, 2005), P. dissecta (Omkar \& Mishra, 2005b) and Coelophora saucia Mulsant (Omkar et al., 2010). Hippodamia convergens appears to differ from these species in that females lack any significant fecundity-stimulation response to multiple matings, although it is possible that such a response might emerge if females were permitted multiple daily copulations with various males, rather than being limited to one.

There was no apparent effect of male mating status, and females did not benefit from the opportunity to choose from among four suitors as compared to arbitrary assignment of a mate, providing no support for either the second hypothesis, that virgin males should have greater impact on female reproduction than previously mated ones, or the third one, that females would benefit from being able to choose among potential mates. Therefore, females improved their fertility simply by mating with different males, as opposed to repeated matings with the same one. Similarly, Hadrill et al. (2007) demonstrated higher fertility (and fecundity) in female $A$. bipunctata mated to ten different males, as compared to those mated ten times to the same male. These results could be attributed to mechanisms of either male or female origin. The presence of sperm from different males may intensify sperm competition within the female reproductive tract and bias fertilization success toward a subset of male gametes with higher average fitness. Alternatively, female fertility might benefit from complementarity among allomonal factors that differ qualitatively among males, independent of sperm competition. On the female side, higher egg fertility might be achieved via some mechanism of post-copulatory female choice. For example, if a proportion of each male's ejaculate contains sperm that is genetically incompatible with the female's gametes, either the female genital tract or the eggs themselves might bias fertilization success toward more genetically compatible sperm (Zeh \& Zeh, 1997), resulting in fewer non-viable zygotes when the sperm of multiple males are present. Finally, if females can recognize individual males, the behavior of mating with a novel male may stimulate females physiologically in ways that matings with familiar males do not, supporting the inference that female sensory perceptions can be a target of sexual selection (Kvarnemo \& Simmons, 2013).

Opportunities for mate choice had no effect on female fecundity or fertility, in contrast to the findings of Omkar \& Mishra (2005b) for P. dissecta. Female choice based on elytral color has been clearly established in species with melanic morphs such as $A$. bipunctata (O'Donald \& Majerus, 1992) and Harmonia axyridis Pallas (Wang et al., 2009, 2013), but evidence for female choice based on other male criteria is largely lacking in the Coccinellidae. The reproductive behavior of $H$. convergens is quite different from that of many other coccinellid species. There are no stereotypical bouts of body-shaking by the male that have been linked to sperm transfer in $H$. axyridis Pallas (Obata, 1987; Wang et al., 2009) and other Asian species (Michaud et al., 2013), so it is not possible to make any inferences about male investment from counts of shaking bouts (Wang et al., 2009, 2013). Copula in H. convergens often lasts longer than one hour, but the duration is highly variable and bears no apparent correlation with female fecundity or fertility (unpubl. data) as it does in many other species (e.g., Omkar et al., 2006). These results caution 
against generalizing among coccinellid species with respect to reproductive behavior and biology.

There were very few discernable differences among mating treatments in paternal effects, and no evidence of paternal effects being stronger for virgin males, or additive among males. However, it is possible that single daily matings were not sufficient to permit summation of paternal effects that might occur when matings are not so limited, as in the male presence experiment. The eggs of monogamous females had the fastest eclosion time, but larval development was faster in the progeny of females multiply-mated to non-virgin males when compared to virgin males, negating the idea that repeated matings with virgin males would provide females greater quantities of male factors contributing to faster progeny development. These finding are in direct contrast to the findings of Michaud et al. (2013) for Coccinella septempunctata L. and Coccinella transversalis F. and those of Mirhosseini et al. (2014) for Cheilomenes sexmaculata (F.) and are thus indicative of substantial interspecific variation in reproductive biology among the Coccinellidae. However, total developmental time did not differ among any planned comparisons, and neither did the fresh body mass of sons or daughters. Thus, polyandry by $H$. convergens, when limited to daily matings, did not appear to benefit offspring via paternal effects deriving from multiple sires, again in contrast to Mirhosseini et al. (2014), although the potential for paternal effects on other aspects of progeny phenotype cannot be ruled out. In addition, the failure of female choice opportunities to improve female reproductive success argues against female ability to select males that will improve fecundity or fertility.

Although the continued presence of a single male had no measurable effect on female $H$. convergens oviposition success compared to a single daily mating, some negative effects of male harassment were evident for females confined with two males, supporting our fifth hypothesis. Although females succeeded in laying similar numbers of eggs in the three treatments, egg fertility was diminished in the two male treatment (Fig. 1). This result suggests that the process of egg fertilization, which occurs as eggs are laid, may be susceptible to behavioral disturbance of the female during oviposition. There was also a non-significant trend toward reduced female survival in the two male treatment (Fig. 2); however, accurate measurement of treatment effects on female longevity would have required a much longer observation period, so it is quite possible the observed differences would have become significant in time.

The progeny of females in the two male treatment had the best survival rate and the fastest larval development and total developmental time, even though these eggs were the slowest to hatch. We infer these results to reflect additive or complementary paternal effects when females were permitted unlimited matings with two males instead of only one, thus supporting our fourth hypothesis of additivity of paternal effects from different males. Similarly, Helsinki \& Harrington (2012) found that daughters of female Aedes aegypti (L.) (Diptera: Culicidae) held at higher male densities had higher fitness than counterparts whose moth- ers were held at lower male densities, even though the former mothers suffered reduced longevity as a consequence of male harassment. Even though both male H. convergens in the two-male treatment likely obtained copulations, they could only do so singly and intermittently, leaving the most recently excluded male to pursue the female subsequent to copulations when she would have been least receptive. One (unquantified) outcome in this treatment was a disruption of egg clustering; frequent disturbance of ovipositing females apparently caused a large number of eggs to be laid singly, as females kept moving to avoid male advances. Similarly, physical disturbance of oviposition by harassing males was inferred to reduce oviposition rate by Callosobruchus maculatus (F.) females (Gay et al., 2008). In $H$. convergens, disruption of egg clustering would have reduced opportunities for sibling egg cannibalism among neonate progeny, which is inferred to be the primary function of egg clustering in aphidophagous coccinellids (Osawa, 1992; Michaud \& Grant, 2004; Pervez et al., 2006). Therefore, reduced opportunities for egg cannibalism among neonates could result a cryptic, but possibly significant, reduction in offspring fitness.

Most insect studies that assessed the impact of continued male presence on female reproduction have usually measured negative impacts. Fox (1993) found no significant differences between the egg production of singly-mated females of $C$. maculatus and those confined with three males and invoked male harassment as one possible explanation for the lack of fecundity stimulation normally resulting from multiple matings in this species. However, subsequent studies on the same species found that egg production was actually reduced by continued male presence (Gay et al., 2008) and that females had lower lifetime reproductive success and shorter longevity when housed with up to four males, when compared to monandrous females (Hollander \& Gwynne, 2009). However, males of this beetle possess a sclerotized intromittent organ with spines that causes cumulative internal damage to the female during copulation, and the fact that females can use copulations to aid in rehydration is an additional complication in this species (Edvardsson, 2007). In a comparable study of Propylea japonica (Thunberg), Mishra \& Omkar (2006) found negative effects for females in the presence of interfering males, but not females; both female fecundity and egg viability were reduced. Whereas in the present study fecundity was not reduced in the presence of two males, it is likely to be at higher male densities, as crowding adults in jars is used routinely in our laboratory as a means of suppressing virtually all oviposition. Any evidence of female fitness costs resulting from male harassment is significant, because it is considered a selective force potentially driving the evolution of "convenience" polyandry (Thornhill \& Alcock, 1983; Arnqvist \& Rowe, 2005) in which females accept a higher frequency of copulation than yields direct reproductive benefits. Male harassment can also drive sexual size dimorphism, if larger females suffer lower harassment costs (Gay et al., 2008), and female $H$. convergens are usually larger than males, as in most Coccinellidae (Nedved 
\& Honek, 2012). It also seems likely that some $H$. convergens matings represent convenience polyandry on the part of females, as there is likely a limit to the number of female matings that result in incremental fitness benefits.

In summary, $H$. convergens egg fertility was improved by providing females access to different males, but their fecundity was not affected. Female reproductive success was unaffected by male mating history or female opportunities for mate choice, although mate choice did cause females to produce 15 clutches in a shorter period. Paternal effects on offspring development did not vary significantly as a function of either polyandry or male mating history, possibly because copulations were limited to one daily. Although the continued presence of two males interfered with female oviposition, disrupting egg clustering and reducing egg viability, offspring development and survival was best in this treatment, suggesting summation of paternal effects when females were allowed to mate ad libitum with two males. We conclude that variation in the paternal effects contributed by different males has the potential to generate fitness benefits for polyandrous females in terms of improved offspring development.

ACKNOWLEDGEMENTS. The authors thank C. Bain for technical support. MHB was supported by a Distinguished Post-Doctoral Fellowship from the Arab Fund for Economic and Social Development, Kuwait. This is contribution no. 14-398-J of the Kansas State Experiment Station.

\section{REFERENCES}

ARnQVist G. \& NiLsson T. 2000: The evolution of polyandry: Multiple mating and female fitness in insects. - Anim. Behav. 60: $145-164$

Arnqvist G. \& Rowe L. 2005: Sexual Conflict. Princeton University Press, Princeton, NJ, 352 pp.

BIND R.B. 2007: Reproductive behaviour of a generalist aphidophagous ladybird beetle Cheilomenes sexmaculata (Coleoptera: Coccinellidae). - Int. J. Trop. Insect Sci. 27: 78-84.

EBerhard W.G. 1996: Female Control: Sexual Selection by Cryptic Female Choice. Princeton University Press, Princeton, NJ, $472 \mathrm{pp}$.

EBerhaRD W.G. 1997: Sexual selection by cryptic female choice in insects and arachnids. In Choe J.C. \& Crespi B.J. (eds): The Evolution of Mating Systems in Insects and Arachnids. Cambridge University Press, Cambridge, UK, pp. 32-57.

Edvardsson M. 2007: Female Callosobruchus maculatus mate when they are thirsty: resource-rich ejaculates as mating effort in a beetle. - Anim. Behav. 74: 183-188.

Fisher D.O., Double M.C., Blomberg S.P., Jennions M.D. \& Cockburn A. 2006: Post-mating sexual selection increases lifetime fitness of polyandrous females in the wild. - Nature 444: 89-92.

Fox C.W. 1993: Multiple mating, lifetime fecundity and female mortality of the bruchid beetle, Callosobruchus maculatus (Coleoptera: Bruchidae). - Funct. Ecol. 7: 203-208.

Gay L., Eady P.E., Vasudav R., Hosken D.J. \& Tregenza T. 2008: Costly sexual harassment in a beetle. - Physiol. Entomol. 34: 86-92.

Hadrill P.R., Shuker D.M., Mayes S. \& Majerus M.E.N. 2007: Temporal effects of multiple mating on components of fitness in the two-spot ladybird. - Eur. J. Entomol. 104: 393-398.
Hadrill P.R., Shuker D.M., Amos W., Majerus M.E.N. \& Mayes S. 2008: Female multiple mating in wild and laboratory populations of the two-spot ladybird, Adalia bipunctata. - Mol. Ecol. 17: 3189-3197.

HelsinKi M.E.H. \& HarRINGTON L.C. 2012: The role of male harassment on female fitness for the dengue vector mosquito $\mathrm{Ae}$ des aegypti. — Behav. Ecol. Sociobiol. 66: 1131-1140.

Hollander M. DEn \& Gwynne D.T. 2009: Female fitness consequences of male harassment and copulation in seed beetles, Callosobruchus maculatus. - Anim. Behav. 78: 1061-1070.

Hosken D.J. \& Stockley P. 2003: Benefits of polyandry: A life history perspective. - J. Evol. Biol. 33: 173-194.

Hosken D.J., Garner T.W.J., Tregenza T., Wedell N. \& Ward P.I. 2003: Superior sperm competitors sire higher-quality young. - Proc. R. Soc. Lond. (B) 270: 1933-1938.

Hunter F.M., Pertie M., Otronen M., Birkhead T. \& Moller A.P. 1993: Why do females copulate repeatedly with one male? - Trends Ecol. Evol. 8: 21-26.

Jennions M.D. \& KoкKo H. 2010: Sexual selection. In Westneat D.F. \& Foz C.V. (eds): Evolutionary Behavioral Ecology. Oxford University Press, Oxford, UK, pp. 343-364.

Jennions M.D. \& Petrie M. 2000: Why do females mate multiply? A review of the genetic benefits. - Biol. Rev. 75: 21-64.

Kvarnemo C. \& Simmons L. 2013: Polyandry as a mediator of sexual selection before and after mating. - Phil. Trans R. Soc. (B) 368: No. 20120042.

Li X.W., Jiang H.X., Zhang X.C., Shelton A.M. \& Feng J.N. 2014: Post-mating interactions and their effects on fitness of female and male Echinothrips americanus (Thysanoptera: Thripidae), a new insect pest in China. — PloS ONE 9(1): e87725.

Madsen T., Shine R., Loman J. \& HaKansson T. 1992: Why do female adders copulate so frequently? - Nature 355: 440-441.

Majerus M.E.N. 1994: Female promiscuity maintains high fertility in ladybirds (Col., Coccinellidae). — Entomol. Mon. Mag. 130: 1564-1567.

Michaud J.P. 2013: Coccinellids in biological control. In Hodek I., van Emden H.F. \& Honek A. (eds): Ecology and Behaviour of the Ladybird Beetles. Wiley-Blackwell, Oxford, UK, pp. 488-519.

Michaud J.P. \& GRant A.K. 2004: The adaptive significance of egg cannibalism in the Coccinellidae: Comparative evidence from three species. - Ann. Entomol. Soc. Am. 97: 710-719.

Michaud J.P., Bista M., Mishra G. \& OMKar 2013: Sexual activity diminishes male virility in two Coccinella species: Consequences for female fertility and progeny development. - Bull. Entomol. Res. 103: 570-577.

Mirhosseini M.A., Michaud J.P., Jalali M.A. \& Ziaaddini M. 2014: Paternal effects correlate with female reproductive stimulation in a polyandrous ladybird, Cheilomenes sexmaculata. - Bull. Entomol. Res. 104: 480-485.

Mishra G. \& OMKar 2006: Conspecific interference by adults in an aphidophagous ladybird Propylea dissecta (Coleoptera: Coccinellidae): effect on reproduction. - Bull. Entomol. Res. 96: 407-412.

Nechols J.R. \& Harvey T.L. 1998: Evaluation of a mechanical exclusion method to assess the impact of Russian wheat aphid natural enemies. In Quisenberry S.S. \& Peairs F.P. (eds): Response Model for an Introduced Pest - The Russian Wheat Aphid. Thomas Say Publications, Lanham, MD, pp. 270-279.

Nedved O. \& HoneK A. 2012: Life history and development. In Hodek I., van Emden H.F. \& Honek A. (eds): Ecology and Behaviour of the Ladybird Beetles. Wiley-Blackwell, Oxford, UK, pp. 54-109. 
OватA S. 1987: Mating behavior and sperm transfer in the ladybird beetle, Harmonia axyridis Pallas (Coleoptera: Coccinellidae). - Appl. Entomol. Zool. 22: 434-442.

Odendaal F.J., Turchin P. \& Stermitz F.R. 1989. Influence of host-plant density and male harassment on the distribution of female Euphydryas anicia (Nymphalidae). - Oecologia 78: 283-288.

O’Donald P. \& Majerus M.E.N. 1992: Non-random mating in Adalia bipunctata (the two-spot ladybird). III. New evidence of genetic preference. - Heredity 69: 521-526.

Olsoon M., Shine R., Madsen T., Gullberg A. \& Tegelstrom H. 1996: Sperm selection by females. - Nature 383: 585.

OMKAR \& JAMES B.E. 2005: Reproductive behaviour of an aphidophagous ladybeetle Coccinella transversalis (Coleoptera: Coccinellidae). - Int. J. Trop. Insect Sci. 25: 96-102.

OMKar \& Mishra G. 2005a: Mating in aphidophagous ladybirds: costs and benefits. - J. Appl. Entomol. 129: 432-436.

OMKar \& Mishra G. 2005b: Evolutionary significance of promiscuity in an aphidophagous ladybird, Propylea dissecta (Coleoptera: Coccinellidae). - Bull. Entomol. Res. 95: 527-533.

OmKar \& Pervez A. 2005: Mating behavior of an aphidophagous ladybird beetle, Propylea dissecta (Mulsant). — J. Insect Sci. 12: $37-44$

OMkar \& SRIVAStava S. 2002: The reproductive behaviour of an aphidophagous ladybeetle, Coccinella septempunctata (Coleoptera: Coccinellidae). - Eur. J. Entomol. 99: 465-470.

Omkar, Singh K. \& Pervez A. 2006: Influence of mating duration on fecundity and fertility in two aphidophagous ladybirds. $-J$. Appl. Entomol. 130: 103-107.

OMKar, Singh S.K. \& Mishra G. 2010: Multiple matings affect the reproductive performance of the aphidophagous ladybird beetle, Coelophora saucia (Coleoptera: Coccinellidae). — Eur. J. Entomol. 107: 177-182.

OsawA N. 1992: Sibling cannibalism in the ladybird beetle Harmonia axyridis: fitness consequences for mother and offspring. - Res. Popul. Ecol. 34: 45-55.

Parker G.A. \& Birkhead T.R. 2013: Polyandry: The history of a revolution. - Phil. Trans. R. Soc. Lond. (B) 368: No. 20120335.

Pervez A. \& Maurice N. 2011: Mate choice and polyandry benefit reproduction and progeny fitness in the ladybird Hippodamia variegata (Goeze). - Eur. J. Environ. Sci. 1: 19-23.

Pervez A., Gupta A.K. \& OmKar 2006: Larval cannibalism in aphidophagous ladybirds: Influencing factors, benefits and costs. - Biol. Contr. 38: 307-313.

RiCE M.E. \& WILDE G.E. 1988: Experimental evaluation of predators and parasitoids in suppressing greenbugs (Homoptera: Aphididae) in sorghum and wheat. - Environ. Entomol. 17: 836-841.
RIDLEY M. 1988: Mating frequency and fecundity in insects. Biol. Rev. 63: 509-549.

Semyanov V.P. 1970: Biological properties of Adalia bipunctata L. (Coleoptera: Coccinellidae) in conditions of Leningrad region. - Zashch. Rast. Vredit. Bolez. 127: 105-112.

Simmons L.W. 2005: The evolution of polyandry: sperm competition, sperm selection, and offspring viability. - Annu. Rev. Ecol. Evol. Syst. 36: 125-146

Slatyer R.A., Mautz B.S., Backwell P.R. \& Jennions M.D. 2012: Estimating genetic benefits of polyandry from experimental studies: a meta-analysis. - Biol. Rev. 87: 1-33.

SRIVASTAVA S. \& OMKaR 2005: Short- and long-term benefits of promiscuity in the seven-spotted ladybird Coccinella septempunctata (Coleoptera: Coccinellidae). - Int. J. Trop. Insect Sci. 25: 176-181.

Thornhill R. \& Alcock J. 1983: The Evolution of Insect Mating Systems. Harvard University Press, Cambridge, MA, ix + 547 pp.

Tregenza T. \& Wedell N. 1998: Benefits of multiple mates in the cricket Gryllus bimaculatus. - Evolution 52: 1726-1730.

Tregenza T. \& Wedell N. 2000: Genetic compatibility, mate choice and patterns of parentage: Invited review. - Mol. Ecol. 9: 1013-1027.

Tregenza T. \& Wedell N. 2002: Polyandrous females avoid costs of inbreeding. - Nature 415: 71-73.

Trivers R.L. 1972: Parental investment and sexual selection. In Campbell B. (ed.): Sexual Selection and the Descent of Man. Heinemann, London, UK, pp. 136-179.

Vargas G.A., Michaud J.P. \& Nechols J.R. 2012a: Cryptic maternal effects in the ladybird beetle Hippodamia convergens vary with maternal age and body size. - Entomol. Exp. Appl. 146: 302-311.

Vargas G.A., Michaud J.P. \& Nechols J.R. 2012b: Larval food supply constrains female reproductive schedules in Hippodamia convergens (Coleoptera: Coccinellidae). - Ann. Entomol. Soc. Am. 105: 832-839.

Wang S., Michaud J.P., Zhang R., Zhang F. \& Liu S. 2009: Seasonal cycles of assortative mating and reproductive behaviour in polymorphic populations of Harmonia axyridis in China. Ecol. Entomol. 34: 483-494.

Wang S., Michaud J.P., Tan X.L., Murray L. \& Zhang F. 2013: Melanism in a Chinese population of Harmonia axyridis (Coleoptera: Coccinellidae): A criterion for male investment with pleiotropic effects on behavior and fertility. - J. Insect Behav. 26: 679-689.

Zен J.A. \& Zен D.W. 1997: The evolution of polyandry. 2. Postcopulatory defences against genetic incompatibility. - Proc. R. Soc. (B) 264: 69-75.

Received May 29, 2014; revised and accepted July 3, 2014 Prepublished online August 19, 2014 